\title{
ANALYSIS OF THE INFLUENCE OF CONVEYOR SPEED ON THE BEHAVIOUR OF AN AUTOMOBILE ASSEMBLY LINE
}

\author{
Ferreira, L.; E. Ares, G.; G.C. Pelaez, L. \& SAlgado, M.
}

Abstract: The work described in this article consists of the development of a simulation model in an Arena environment, based on a real case, and is aimed at a very specific class of production lines, with a four closed-loop network configuration. The purpose of the use of an Arena simulation environment was that of enabling the production engineer to evaluate the performance of the automobile assembly line, through the variation of different parameters, thus contributing to an improved specification, characterisation and definition of the most efficient control system.

In this paper we analyze the influence of the speed of the intermediate buffers formed by conveyors in assembly line performance, which has still not been researched in specialist literature. In order to obtain the functions that describe the behaviour of the assembly system, the design of an experiments technique was used.

Key words: simulation, automobile assembly lines, manufacturing
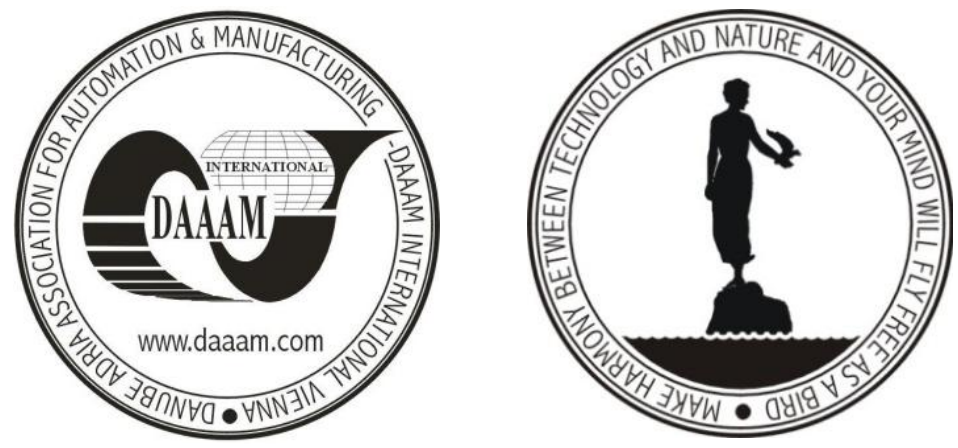

Authors' data: Univ.Prof. Dipl.-Ing.Ferreira, L[uis]*;Univ.Prof. Dipl.-Ing. Ph`D. Eng. E. Ares, G[omez]**; Univ. Prof. Dipl.-Ing. Ph`D. Eng. G.C Pelaez, L[ourido]** \& Dipl.-Ing. Salgado, M[arina]**, *Escola Superior de Estudos Industriais e de Gestão, Instituto Politécnico do Porto, Portugal, **Área Ingeniería de los Procesos de Fabricación, Universidad de Vigo, Spain, luispintoferreira@eu.ipp.pt, enrares@uvigo.es,gupelaez@uvigo.es,marina.salgado@uvigo.es

This Publication has to be referred as: Ferreira, L[uis]; E. Ares, G[omez]; G.C Pelaez, L[ourido] \& Salgado, M[arina] (2010). Analysis of the Influence of Conveyor Speed on the Behaviour of an Automobile Assembly Line, Chapter 41 in DAAAM International Scientific Book 2010, pp. 463-470, B. Katalinic (Ed.), Published by DAAAM International, ISBN 978-3-901509-74-2, ISSN 1726-9687, Vienna, Austria DOI:10.2507/daaam.scibook.2010.41 
Ferreira, L.; E. Ares, G.; G.C. Pelaez, L. \& Salgado, M.: Analysis of the Influence ...

\section{Introduction}

Simulation allows the imitation of a system's behaviour through the use of a model developed on computer. By simulating, one is able to deal with a model representing its virtual process and not the real process itself. Using this resource, it becomes possible to create changes in the process in numerous ways. For example, one can modify layouts, operation rules, insert or eliminate equipment, people, amongst other possibilities; one can also immediately evaluate the impact of these changes on the productivity and efficiency of a business or organisation. Basically, simulation constitutes ona technique which allows transferring reality into the computer, through the creation of a model that accurately mirrors the behaviour of a process (in existence or in its project phase). Using the "virtual" model, it's possible to test solutions, predict bottle necks and behaviour, as well as obtain answers without having to alter reality. Thus, simulation techniques include not only the modeling of problems but also the experimentation of the selfsame model with the purpose of evaluating its performance and/or tailoring the system's components, when in real operation (Ferreira et al. 2004). According to O'Kane et al. (2000) in (Montevechi et al. 2007), simulation has become one of the most popular techniques in the analysis of complex problems in the production sector. Computer simulation is particularly useful in analyzing systems which incorporate randomness in their parameters or when there are no exact analytical solutions (Lucko et al. 2008).

The work presented in this article consists of the development of a simulation model in an Arena environment, based on a real case, and covers a very specific class of production lines, with the configuration of a network of four closed loops, which is very common in the automobile sector. This study is a sequence of another, developed by (Resano 2007, Resano \& Luis Pérez 2007a, Resano \& Luis Pérez 2007b, Resano \& Luis Pérez2007c), who designed one of the first analytical models for an assembly line in the automobile sector as a network of four closed loops of machines decoupled by intermediate buffers formed by conveyors. They consider that machines process pallets, which are not univocally related to each other. Both in the analytical model, as well as in the simulation presented here, one can analyse the blocking and starvation phenomena on a complex production line; these also consider the proportion of four- and two-door cars between the sections of door disassembly and assembly stations. Regardless of the importance of developing different models in a simulated environment, which allows the analysis and optimization of these types of automobile assembly lines, there is no knowledge of specialist literature, nor of any other study that considers all these factors, even though these are especially relevant in the performance of manufacturing lines of this type.

\section{Model of the Assembly Line}

Figure 1 represents the main automobile line as well as the doors and front axle preassembly lines as a network of four closed-loop machines and intermediate buffers formed by conveyors. 


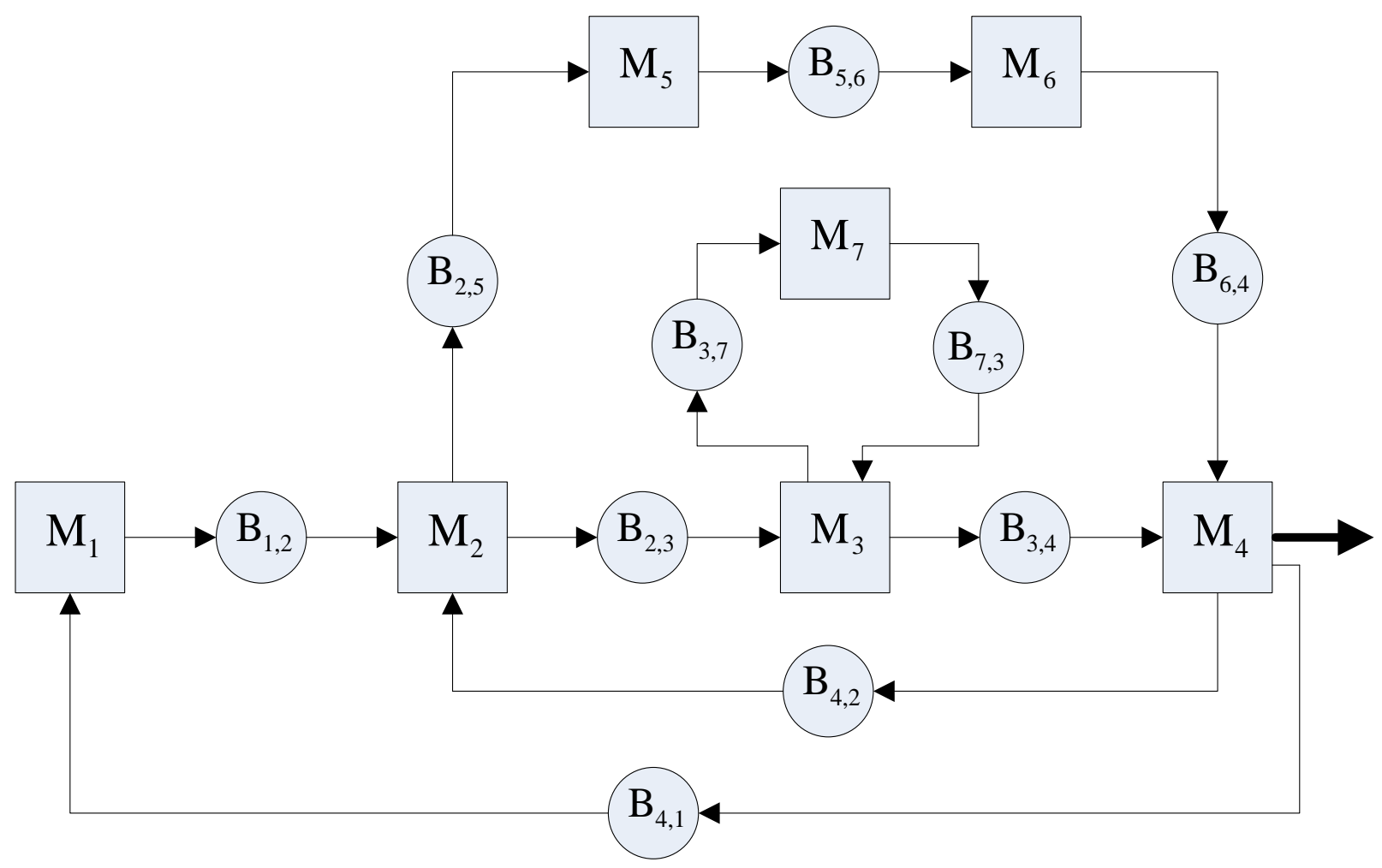

Fig. 1. Main automobile assembly line and preassembly lines

The sum of the car bodies, doors and front axle assembly pallets stored in each of the intermediate buffers of the three first closed-loops remain, respectively, constant at any time and are defined by Equations (1) to (3). This fact, as well as other analyses undertaken to evaluate the influence of different variables which interfere in the performance of the automobile assembly line being studied, was previously analysed in (Resano 2007, Resano \& Luis Pérez2007a, Resano \& Luis Pérez 2007b, Resano \& Luis Pérez2007c).

$$
\begin{aligned}
& \mathrm{n}_{12}+\mathrm{n}_{23}+\mathrm{n}_{34}+\mathrm{n}_{41}=237 \\
& \mathrm{n}_{25}+\mathrm{n}_{56}+\mathrm{n}_{64}+\mathrm{n}_{42}=450 \\
& \mathrm{n}_{37}+\mathrm{n}_{73}=138
\end{aligned}
$$

The fourth closed-loop defines the relationship between the number of pallets with doors in different preassembly states and the number of pallets of cars with disassembled doors via an external variable (x), according to Equation (4). This variable represents the four-door car ratio between the doors' disassembly stations, located at $\mathbf{M}_{2}$, and the doors' assembly stations, located at $\mathbf{M}_{4}$. This variable can take on values between 0 and 1 .

$$
\mathrm{n}_{25}+\mathrm{n}_{56}+\mathrm{n}_{64}+\mathrm{n}_{5}+\mathrm{n}_{6}=\left(\mathrm{n}_{2}+\mathrm{n}_{3}+\mathrm{n}_{4}+\mathrm{n}_{23}+\mathrm{n}_{34}\right) \cdot(1+\mathrm{x})
$$


Ferreira, L.; E. Ares, G.; G.C. Pelaez, L. \& Salgado, M.: Analysis of the Influence ...

Where $\mathrm{n}_{5}$ and $\mathrm{n}_{6}$ are the numbers of stations $\mathrm{M}_{5}$ and $\mathrm{M}_{6}, \mathrm{n}_{2}$ is the number of stations at $\mathrm{M}_{2}$, from the door disassembly stations, $\mathrm{n}_{3}$ is the number of stations at $\mathrm{M}_{3}$ and $\mathrm{n}_{4}$ is the number of stations at $\mathrm{M}_{4}$ to the door assembly stations. The values of $\mathrm{n}_{2}, \mathrm{n}_{3}, \mathrm{n}_{4}, \mathrm{n}_{5}$ and $\mathrm{n}_{6}$ remain constant. Replacing the sum of their values in Eq. (4) the following is obtained

$$
\mathrm{n}_{25}+\mathrm{n}_{56}+\mathrm{n}_{64}+60=\left(216+\mathrm{n}_{23}+\mathrm{n}_{34}\right) \cdot(1+\mathrm{x})
$$

The simulation model presented in this article is based on these equations in order to determine the number of pallets which must circulate on each of the 4 closed-loops which exist on the analyzed automobile assembly line.

\section{Characteristics of the Developed Support System for Decision-Making}

In the context of this Project, all the work was developed in an Arena simulation environment (Kelton et al. 2007), whose simulation language represents a visual and flexible programming tool, directed at the object, since it simultaneously combines the construction of simulation models with the integration of different languages of general use: Visual Basic, $\mathrm{C}, \mathrm{C}^{++}$. This language is based on the SIMAN simulation language (Takus \& David 1997).

The purpose of the use of an Arena simulation environment was that of enabling the production engineer to evaluate the performance of the automobile assembly line, through the variation of different parameters, thus contributing to an improved specification, characterisation and definition of the most efficient control system.

With this objective in mind, a support system for decision-making was developed; this enables the automatic generation of different simulation models, allowing the user in the initial stage of simulation to interact with the system to be developed, through the introduction of various parameters such as:

- The four-door cars ratio (x);

- The processing time for each machine;

- The production sequence in accordance with each type of car (two- or fourdoor);

- The speed and length of the intermediate buffers formed by conveyors;

- Simulation time;

- The number of pallets circulating on the first three closed-loops.

Figure 2 presents the graphic interface which allows the user to configure the above mentioned parameters. 


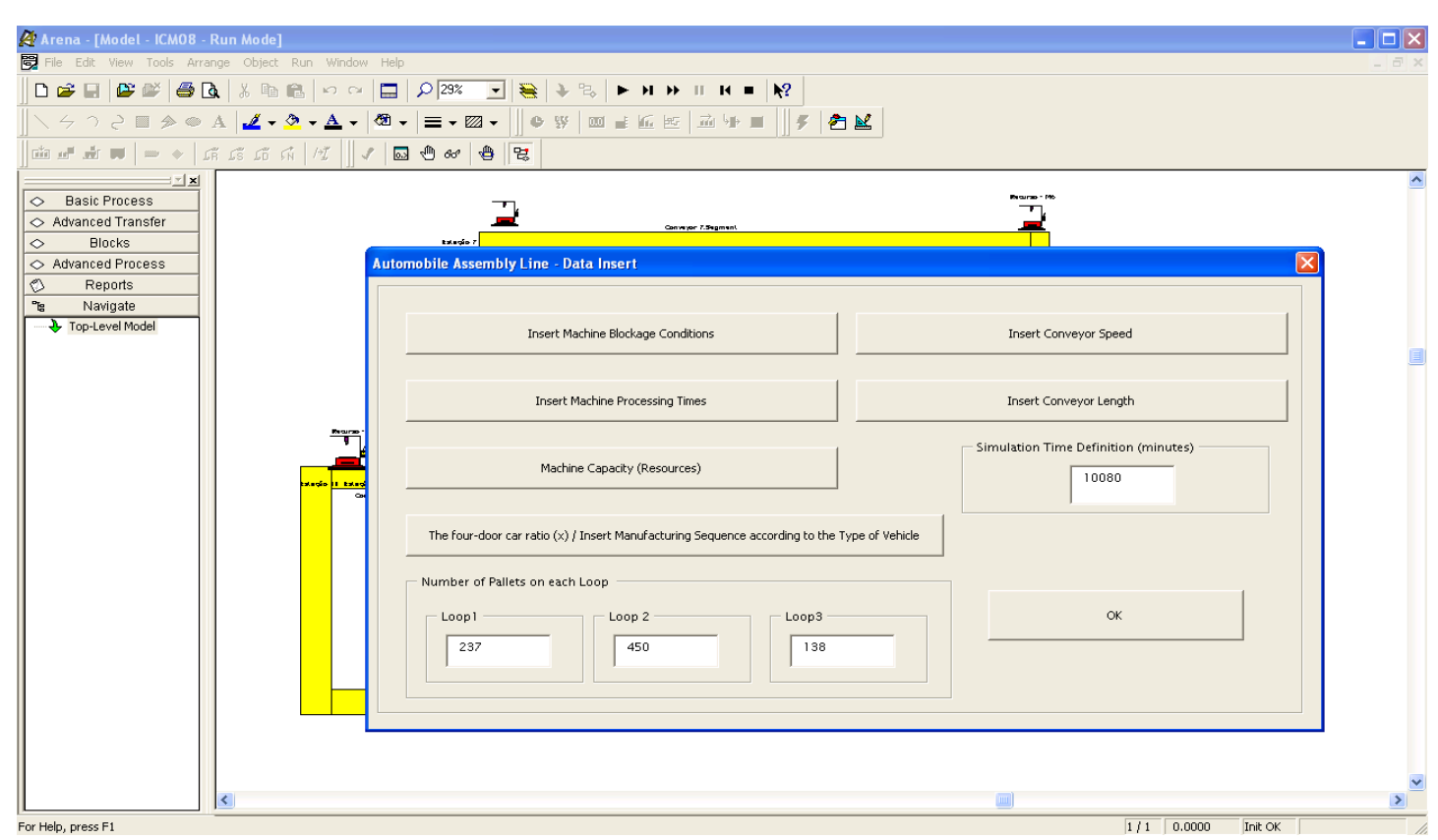

Fig. 2. Parameterization of the automobile assembly line

\section{An assessment of the Impact of the Intermediate Buffers' Speed formed by Conveyors on the Number of Vehicles Produced per Hour $(X=0,7)$}

Through the developed decision-making support system, one sought to assess the influence of the speed variation of the first three closed loops on the production line performance. In the real model, the value used for the proportion of four-door cars was that of 0,7 ; the reference values for the first three closed loops were, respectively, $16 \mathrm{~m} / \mathrm{min}, 25 \mathrm{~m} / \mathrm{min}$ and $45 \mathrm{~m} / \mathrm{min}$.

Figure 3 enables one to observe the speed variation of the intermediate buffers formed by conveyors (Loop 1) according to the number of cars per hour. One can thus conclude that for speeds above or equal to $10 \mathrm{~m} / \mathrm{min}$, the number of cars produced/hour will remain constant, the value being that of approximately 55,5 cars/hour.

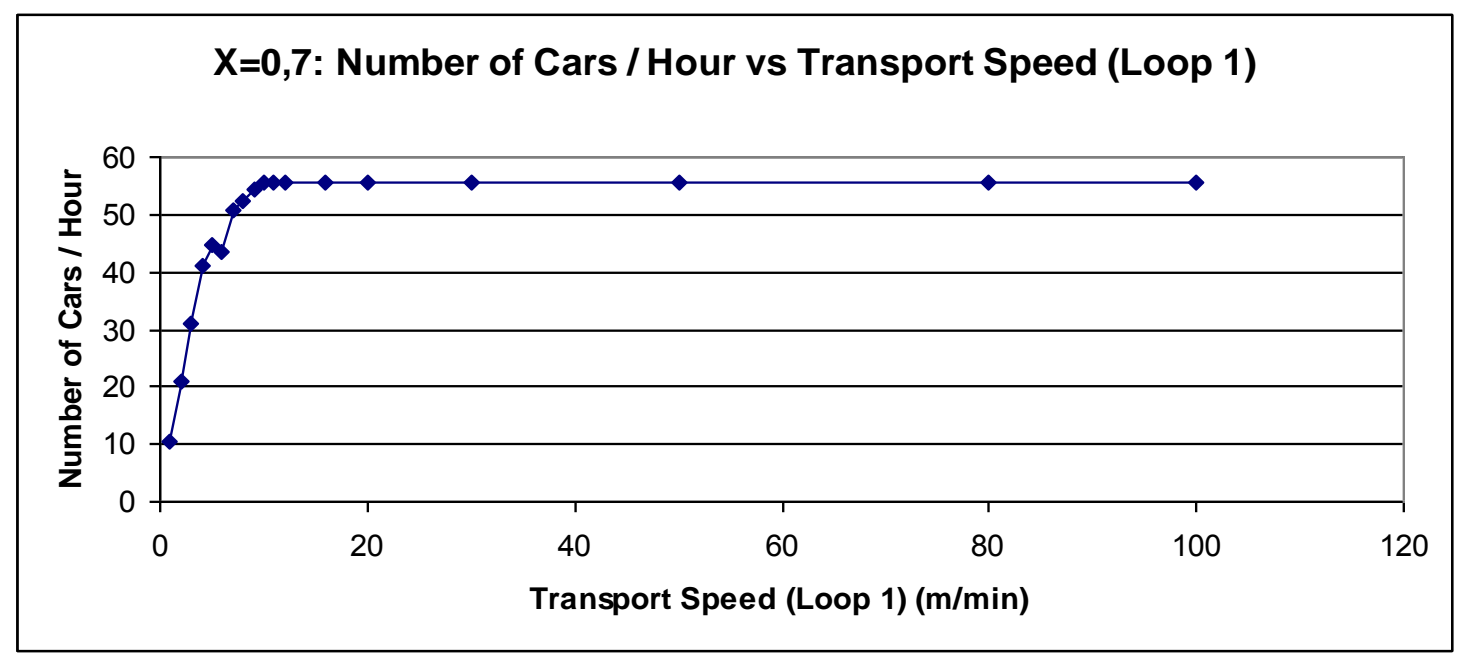

Fig. 3. Intermediate Buffers' Speed Formed by Conveyors in Loop 1 According to the Number of Cars per Hour $(\mathrm{X}=0,7)$ 
Ferreira, L.; E. Ares, G.; G.C. Pelaez, L. \& Salgado, M.: Analysis of the Influence ...

Figure 4 enables one to observe the intermediate buffers speed variation formed by conveyors (Loop 2) according to the number of cars per hour. Here, one concludes that, for speeds above or equal to $6 \mathrm{~m} / \mathrm{min}$, the number of cars produced/hour will remain constant, the value being that of approximately 55,5 cars/hour.

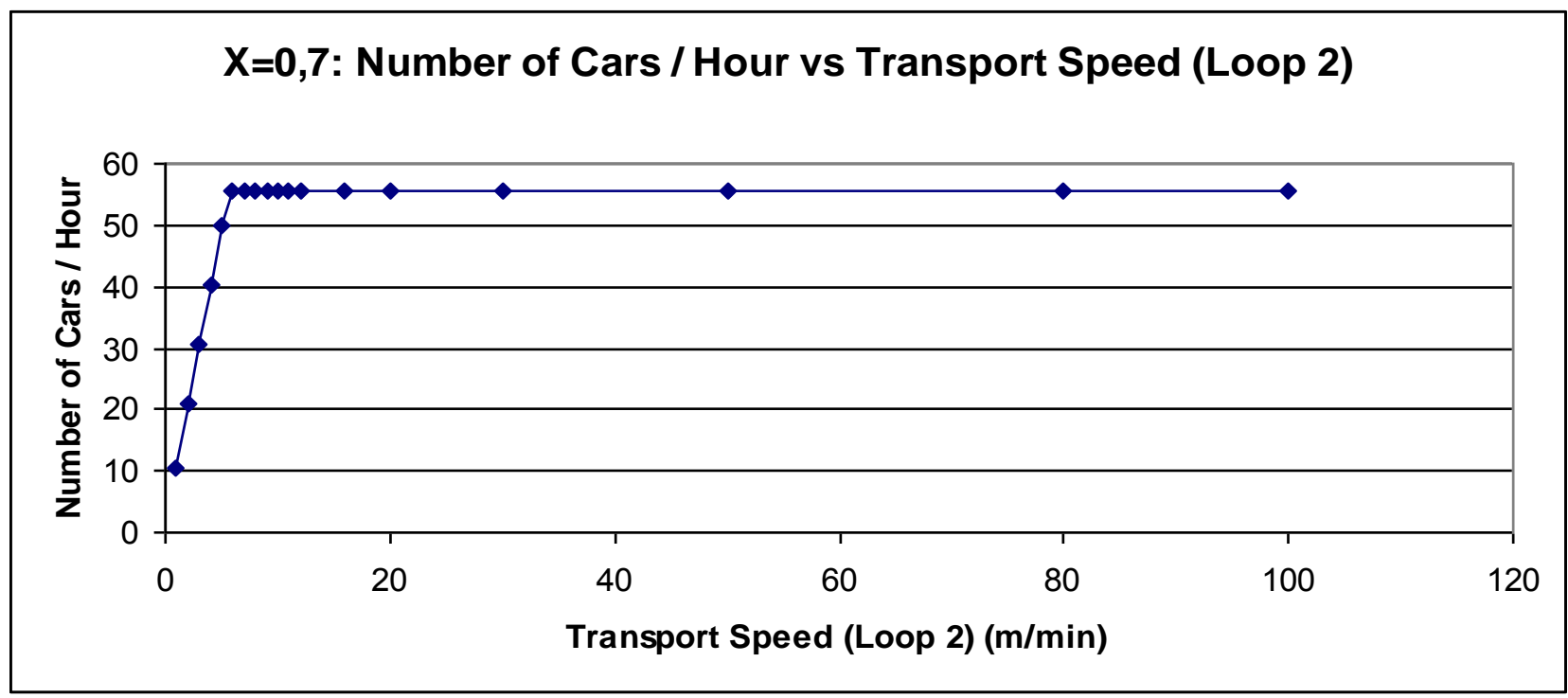

Fig. 4. Intermediate Buffers' Speed Formed by Conveyors in Loop 2 According to the Number of Cars per Hour $(\mathrm{X}=0,7)$

Figure 5 presents the speed variation of the intermediate buffers formed by conveyors (Loop 3) according to the number of cars per hour. On analyzing this, one can verify that, for speeds above or equal to $6 \mathrm{~m} / \mathrm{min}$, the number of cars produced/hour will remain constant, the value being that of approximately 55,5 cars/hour.

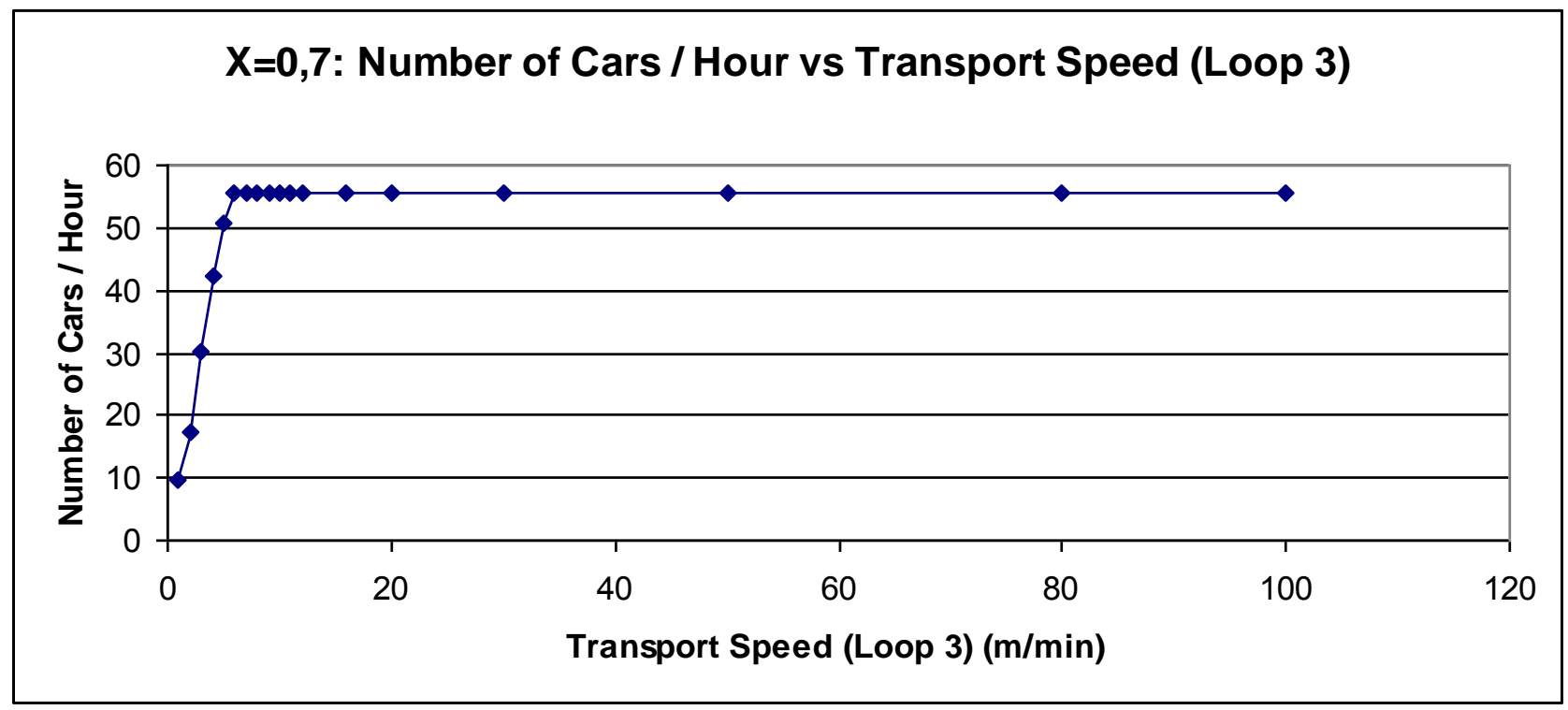

Fig. 5. Intermediate Buffers' Speed Formed by Conveyors in Loop 3 According to the Number of Cars per Hour $(\mathrm{X}=0,7)$ 
On observing the contents of figures 3,4 and 5, one can conclude that it is possible to decrease the speed of the intermediate buffers formed by conveyors in the first three closed loops without jeopardizing the production line. Table 1 presents a summary table of the proposed values constituting the limits for speed reduction in the first three closed loops. This fact has proved to be of the utmost importance in the sense that it potentially allows a reduction of the energy costs ensuing from the running of the conveyors. One is, therefore, dealing here with a relevant observation which, however, has not been referred to in literature of the specialty until now.

\begin{tabular}{|c|c|c|c|}
\hline$X=0,7$ & $\begin{array}{r}\text { Inte } \\
\mathrm{S}\end{array}$ & $\begin{array}{l}\text { e Buffers' } \\
\text { med by } \\
\text { yors }\end{array}$ & $\begin{array}{l}\text { Number of } \\
\text { Cars / Hour }\end{array}$ \\
\hline \multirow{3}{*}{ Real Model } & Loop 1 & $16 \mathrm{~m} / \mathrm{min}$ & \multirow{3}{*}{55,5} \\
\hline & Loop 2 & $25 \mathrm{~m} / \mathrm{min}$ & \\
\hline & Loop 3 & $45 \mathrm{~m} / \mathrm{min}$ & \\
\hline \multirow{3}{*}{$\begin{array}{l}\text { Proposal } \\
\text { for Alteration } 1\end{array}$} & Loop 1 & $10 \mathrm{~m} / \mathrm{min}$ & \multirow{3}{*}{55,5} \\
\hline & Loop 2 & $25 \mathrm{~m} / \mathrm{min}$ & \\
\hline & Loop 3 & $45 \mathrm{~m} / \mathrm{min}$ & \\
\hline \multirow{3}{*}{$\begin{array}{l}\text { Proposal } \\
\text { for Alteration } 2\end{array}$} & Loop 1 & $16 \mathrm{~m} / \mathrm{min}$ & \multirow{3}{*}{55,5} \\
\hline & Loop 2 & $6 \mathrm{~m} / \mathrm{min}$ & \\
\hline & Loop 3 & $45 \mathrm{~m} / \mathrm{min}$ & \\
\hline \multirow{3}{*}{$\begin{array}{l}\text { Proposal } \\
\text { for Alteration } 3\end{array}$} & Loop 1 & $16 \mathrm{~m} / \mathrm{min}$ & \multirow{3}{*}{55,5} \\
\hline & Loop 2 & $25 \mathrm{~m} / \mathrm{min}$ & \\
\hline & Loop 3 & $6 \mathrm{~m} / \mathrm{min}$ & \\
\hline
\end{tabular}

Tab. 1. Intermediate Buffers' Speed Formed by Conveyors according to the number of cars per hour $(X=0,7)$

\section{Conclusions}

In this paper, an automobile assembly line and different preassembly lines were modelled as a network of four closed-loop machines and intermediate buffers formed by conveyors, constituting a configuration which is widely used in these kinds of assembly lines. Using an Arena simulation environment, a representative model of this line was developed with the purpose of providing the production engineer with a better understanding and assessment of its performance. The most relevant conclusion of the work presented in this article resides in the fact that it is possible to decrease the intermediate buffers' speed formed by conveyors in the first three closed-loops without jeopardizing the performance of the automobile production line. This possibility is proved to be of the utmost importance, since it allows a reduction in the energy costs associated with the operation of the conveyors. The authors believe that, by producing this study, they have contributed to emphasising the importance of 
Ferreira, L.; E. Ares, G.; G.C. Pelaez, L. \& Salgado, M.: Analysis of the Influence ...

computer simulation use in the development of virtual environments, which reproduce the behaviour of many real systems. However the simulation doesn't supply optimal solutions for the problems in study - it allows, though, evaluating the system behaviour by certain scenarios, for that effect created by the analyst.As perspectives of future work, some actuation lines stand out, as a natural continuation of the proposals presented here:

- Impact evaluation of the number of pallets in circulation in the first three closed-loops in the automobile assembly line performance.

- Behaviour evaluation of the production line when a new car type is inserted.

\section{References}

Ferreira, Luís Pinto; João Macedo \& Ana Soares (2004). "Suporte Operacional à Tomada de Decisões através da Simulação - O Caso de uma Grande Superfície Comercial", Painel - "Organização e Gestão Industrial", Actas das $4^{a s}$ Jornadas Politécnicas de Engenharia (CD-ROM), Instituto Superior de Engenharia do Porto (ISEP), 17-18 Novembro 2004, Portugal

Kelton, W. David; Randall P. Sadowski \& David T. Sturrock, (2007). "Simulation With Arena", Fourth Edition, McGraw-hill Series, ISBN-10: 0-07-110685-5

Lucko, Gunnar Lucko; Perakath C. Benjamin \& Michael G. Madden (2008). "Harnessing the Power of Simulation in the Project Management / Decision

Support Aspects of the Construction Industry", in Proceedings of 2008 Winter Simulation Conference

Montevechi, José Arnaldo Barra, Alexandre Ferreira de Pinho, Fabiano Leal \& Fernando Augusto Silva Martins (2007). "Application of Design of Experiments on the Simulation of a Process in an Automotive Industry", in Proceedings of 2007 Winter Simulation Conference

Resano, A. (2007). "Análisis Funcional y Optimización de la Distribuición en Planta de una Línea de Ensamblaje de Automóviles", PhD Thesis, directed by Prof. C. J Luis Pérez. Departamento de Ingeniería Mecánica, Energética y de Materiales, Universidad Pública de Navarra

Resano, A. \& C. J. Luis Pérez, (2007a). "Analysis of an automobile assembly line as a network of closed loops working in both, stationary and transitory regimes". International Journal of Production Research

Resano, A. \& C. J. Luis Pérez, (2007b). "Analysis and enhancement of the four-door cars proportion limits in a real automobile assembly line working in transitory regime", Second Manufacturing Engineering Society International Conference. Madrid. Spain

Resano, A. \& C. J. Luis Pérez, (2007c). "Dynamic analysis of an automobile assembly line considering starving and blocking". Robotics and Computer Integrated Manufacturing, Article in Press. DOI:10.1016/j.rcim.2007.11.002

Takus, David A. Takus \& David M. Profozich (1997). "ARENA Software Tutorial”, in Proceedings of 1997 Winter Simulation Conference 